\title{
Most prevalent unmet supportive care needs and quality of life of breast cancer patients in a tertiary hospital in Malaysia
}

\author{
Zobaida Edib ${ }^{1 *}$, Verasingam Kumarasamy ${ }^{1}$, Norlia binti Abdullah², A. M. Rizal ${ }^{3}$ and Sami Abdo Radman Al-Dubai ${ }^{4}$
}

\begin{abstract}
Background: Addressing breast cancer patients' unmet supportive care needs in the early stage of their survivorship have become a prime concern because of its significant association with poor quality of life (QOL), which in turn increases healthcare utilization and costs. There is no study about unmet supportive care needs of breast cancer patients in Malaysia. This study aims to assess the most prevalent unmet supportive care needs of Malaysian breast cancer patients and the association between $\mathrm{QOL}$ and patients' characteristics, and their unmet supportive care needs.

Methods: A cross-sectional study was conducted at the Surgery and Oncology Clinic between May 2014 and June 2014 in a tertiary hospital in Malaysia. A total of 117 patients out of 133 breast cancer patients recruited by universal sampling were interviewed using a structured questionnaire consisted of three parts: participants' sociodemographic and disease characteristics, Supportive Care Needs Survey-Short Form Questionnaire (SCNS-SF34) and European Organization for Research and Treatment of Cancer Quality of Life Questionnaire C30 (EORTC QLQ-C30).

Results: The highest unmet supportive care needs were observed in the psychological domain (Mean 53.31; SD \pm 21.79), followed by physical domain (Mean 38.16; SD \pm 27.15 ). Most prevalent unmet supportive care needs were uncertainty about the future (78.6\%), fears about the cancer spreading (76.1\%), feelings of sadness (69.2\%), feelings about death and dying (68.4\%), concerns about those close to the patient (65.0\%) and feeling down or depressed (65.0\%). Multivariate linear analysis showed that early breast cancer survivors diagnosed at an advanced stage and with greater physical and psychological needs were significantly $(p<0.05)$ associated with poorer QOL.

Conclusion: Most prevalent unmet needs among Malaysian breast cancer patients were found in the psychological domain. Early breast cancer survivors with late stage diagnosis who had more unmet needs in psychological and physical domains were more likely to have a poor QOL.
\end{abstract}

Keywords: Supportive care, Unmet needs, Quality of life, Breast cancer

\section{Background}

Worldwide the most frequently diagnosed cancer among women is the cancer of breast [1]. About half of the breast cancer cases and $60 \%$ of the deaths are estimated to occur in economically developing countries [2]. The breast cancer incidence rates in Malaysia has increased during last three decades at an alarming rate and become an inevitable threat to women. It is estimated that

\footnotetext{
* Correspondence: dr.zobaidaedib@gmail.com

${ }^{1}$ Department of Community Medicine, International Medical University, Bukit Jalil 57000 Kuala Lumpur, Malaysia

Full list of author information is available at the end of the article
}

one in 19 women in Malaysia are at lifetime risk, compared to one in 8 in Europe and the United States [2]. Increased awareness, early detection, combination treatment of chemotherapy, irradiation, hormone therapy and advancement of target therapies, as well as better characterization of prognostic factors have remarkably improved the survival rate of women with breast cancer worldwide [3, 4]. The five-year survival rate in the west is 70 to $90 \%$, in developing countries $57 \%$ and globally $61 \%$ $[5,6]$. In Malaysia, the five-year survival rate for breast cancer is $49 \%$ with median interval of 68.1 months and is continuing to escalate every year [7]. 
Cancer survivorship is an unremitting struggle as the consequence of complex treatment process and it's multitude of residual and late emerging side effects that have significant impact on physical, psychological, sexual, social and sometimes financial disturbances throughout the post-treatment phase [8-11]. This is considered to be a major aspect that gives rise to multiple unmet needs for breast cancer survivors [12]. Supportive care helps a cancer patient cope with the disease throughout the process of diagnosis, treatment and post-treatment phases [13]. Supportive care is defined as rendering essential services that satisfy cancer patients' physical, psychological, social, informational and spiritual needs over the entire illness trajectory [14, 15]. Although it is acknowledged as an essential service, 1$93 \%$ of cancer patients' supportive needs have been consistently unmet $[15,16]$. There is growing evidence that the needs perceived by breast cancer patients and the support being provided by the healthcare professionals are diverse $[8,17,18]$. Hence, it is found that the breast cancer patients mostly suffer from physical, emotional, social, financial and psychological disturbances to a greater extent and unmet needs were highest in the post-treatment phase compared to the other phases of cancer continuum $[10,15,19,20]$. Supportive care is an essential buffering component of cancer patients that helps to regain emotional stability, social adjustment, cognitive function, body image, future perspective and physical strength [21-24].

Understanding the full impact of unmet needs of the breast cancer patients on their QOL is crucial and clinically of prime importance throughout their continuum of survivorship to offer timely effective interventions. Many studies have found that most unmet needs were in the early stage of cancer survivorship that had detrimental effects on QOL of cancer patients [25-27]. However, several studies suggesting that greater supportive care was associated with long survival and better QOL [27-29]. Thus improving the QOL of breast cancer patients requires addressing the unmet supportive care needs of the breast cancer patients [30]. Assessing needs also offer a direct measure of the patients' support preference and service gaps [31]. Studying the perception of the breast cancer patients' unmet supportive care needs clarifies where actions and resource allocation are necessary in healthcare setting to help the patients to overcome their difficulties.

Effective high quality management in healthcare setting is accounted as more than just delivery of anticancer therapy $[22,32]$. However, it focuses on identification of unsatisfied needs of cancer patients that provides the opportunity to enhance the QOL, which in turn also reduces health care utilization and costs [33-37]. Evaluating these unmet supportive care needs of the breast cancer patients enables healthcare providers to identify those which lack the level of service or support they perceive essential to achieve the optimal quality of life (QOL). In this context, addressing breast cancer patients' unmet needs in the early stage of their survivorship provides rationale to enhance their QOL and guidance for new strategies in healthcare setting that could potentially reduce the burden of this disease and treatment in the long run and thereby improve their QOL. Existing knowledge on unmet supportive care needs of the breast cancer patients and QOL is predominantly from the western countries. However, there is no evidence of addressing unmet supportive care needs of breast cancer patients and how it is associated with QOL in Malaysia. This study aims to assess the most prevalent unmet supportive care needs of breast cancer patients and the association between QOL and these patients' characteristics, and their unmet supportive care needs in a tertiary hospital in Malaysia.

\section{Methods \\ Study design and sample}

A cross-sectional study was conducted at the Surgery and Oncology Clinic on Clinic Day in University Kebangsaan Malaysia Medical Centre (UKMMC) between May 2014 and June 2014 among breast cancer patients. Inclusion criteria for recruiting the patients were: female primary and recurrent breast cancer patients of all ages and with any stages, who had survived at least one year after being diagnosed by a registered physician, must be Malaysian and who can speak either English or Malay. Excluded from this study were those who had secondary breast cancer and were terminally ill and those who were not able to speak.

\section{Instruments}

A structured questionnaire was used in this study which consisted of the following parts: participants' sociodemographic and disease characteristics, Supportive Care Needs Survey -Short Form (SCNS-SF 34) and European Organization for Research and Treatment of Cancer Quality of Life Questionnaire C30 (EORTC QLQ-C30). SCNS-SF34 is a standardised instrument for measuring cancer patients' perceived needs across a range of domains. A total number of 34-items are divided into five domains: physical/daily living (5 items), psychological (10 items), sexuality (3 items), patient care and support (5 items) and health system and information needs (10 items). Internal consistency was high with Cronbach's alpha coefficients for the five domains ranging from 0.87 to 0.96 [38]. A five-point rating scale ( $1=$ no need $/$ not applicable, $2=$ no need $/$ satisfied, $3=$ low need, $4=$ moderate need and $5=$ high need) is used 
to rate the levels of need over the past month. Standardised likert summated score was used to score SCNSSF34 according to Supportive Care Needs Survey scoring manual. The score has possible values ranging from 0 to 100, with a higher score indicating more unmet needs [39]. EORTC QLQ-C30 is a standardized questionnaire which was constructed by the EORTC Quality of Life Study Group to measure the quality of life of cancer patients. The linear transformation of the raw score of the global QOL was done according to EORTC scoring manual to standardize the raw score so that it ranges from 0 to100 [40]. The correlation coefficient for global QOL was 0.85 [41].

The Malay version of the questionnaire was prepared for the participants who cannot speak English. The questionnaire was translated into Malay language by an independent language expert who was not associated with this study. This Malay version of the questionnaire was then back-translated into English by another independent language expert not associated with this study. This second English version of the questionnaire was then re-translated into Malay by another independent language expert not associated with this study. Both the two sets of English and Malay version were subsequently compared with the original version by the Breast and Reconstructive Surgeons for the conceptual equivalence of the items. Then the final questionnaire was verified by the Surgery Department of UKMMC and the Community Medicine Department of International Medical University. Minor modifications were made wherever applicable to the translated questionnaires to remove discrepancies. Pre-testing was done on a sample of eight breast cancer patients at the Surgery Clinic of UKMMC to assess the acceptance and time management.

\section{Ethical consideration}

The study was approved by Medical Ethics Committee of International Medical University (Project Number: M.ScPHI01/2014(01) and Research Ethics Committee of Universiti Kebangsaan Malaysia Medical Centre (Approval Number: 1.5.3.5/244/FF-2014-255).

\section{Procedure}

A convenience sample of 133 breast cancer patients defined by the sampling criteria were recruited from the Surgery and Oncology out-patient clinic of UKMMC. The study was conducted on a voluntary basis where the selected participants voluntarily agreed to take part in this study. Out of total 133 breast cancer patients, 117 patients voluntarily agreed to take part in the study and gave their written informed consent. Participants were well informed about the purpose of the study and reassured that all the personal information will be kept confidential, and they could withdraw their consent anytime without giving any reason. In addition to that, briefing on the questionnaire in both English and Malay was conducted to ensure the accuracy of collecting information. The participants were allowed to enquire any questions related to the questionnaire. Data were obtained through interviewer-administered questionnaire to ensure the quality of collected information and reduce the refusal rate. Two trained interviewers were assigned for the briefing of the study, securing written informed consent and for conducting the interviews under the direct supervision of the researcher. However, the interviewers and the researcher had no relation with the participants.

\section{Data analysis}

Data were tabulated and analysed by using the Statistical Package for the Social Sciences version 20.0 (SPSS Inc.; Chicago, IL, USA). Descriptive analysis was used for demographic and disease characteristics as well as supportive care needs items. Mean, median scores and standard deviation (SD) were calculated for supportive care needs' domains. Univariate analyses of the relationship between the global QOL and domains of supportive care needs, and participants' socio-demographic and disease characteristics were examined by the means of independent $t$-test, one way analysis of variance (ANOVA) and Pearson correlation coefficient, as appropriate. All variables with $p$ value $<0.25$ in univariate analyses were chosen for multiple linear regression to determine the variables that were independently associated with global QOL. All tests of significance were two-sided and with $p$ value $<0.05$ was considered as statistically significant.

\section{Results}

\section{Socio-demographic and disease characteristics of the} participants

Total 117 patients were agreed to participate in this study out of 133 breast cancer patients defined by the inclusion and exclusion criteria (response rate $=88.0 \%$ ). A summary of the participants' socio-demographic and disease characteristics are provided in the Table 1. More than half of the participants aged 50 years and above (61.6\%). The majority were Malay (58.1\%), followed by Chinese $(29.9 \%)$ and Indian (12.0\%). About $13 \%$ of the participants reported that they had no formal education and $16.3 \%$ had only primary education, while almost one-third $(31.6 \%)$ had a tertiary level of education. The majority of the participants were married $(77.8 \%)$. Of the total participants, half of them were housewife (53.8\%) followed by employed (31.6\%) and retired (14.5\%). Among the participants $41.0 \%$ had a household income between RM2000 and RM4000. 
Table 1 Socio-demographic and disease characteristics of participants $(n=117)$

\begin{tabular}{lll}
\hline $\begin{array}{l}\text { Socio-demographic and } \\
\text { disease characteristics }\end{array}$ & Total sample (117) \\
\cline { 2 - 3 } & $\mathrm{N}$ & $\%$ \\
\hline
\end{tabular}

Age

$$
\begin{gathered}
<40 \text { years } \\
40-49 \text { years } \\
\geq 50 \text { years } \\
\text { Ethnicity }
\end{gathered}
$$

Malay

Chinese

Indian

Educational level

No formal education
Primary
Secondary
Tertiary
Marital status
Unmarried
Married

Divorced/widowed

Employment status

Housewife
Employed
Retired

Household income (RM)

Less than 2000

$2000-4000$

More than 4000

Time since diagnosis

$$
\begin{aligned}
& <2 \text { years } \\
& 2-5 \text { years } \\
& >5 \text { years }
\end{aligned}
$$

16

29

72

68

35

14

15

19

46

37

4

91

22

63

37

17

41

48

28

13.7

24.8

61.6

58.1

29.9

12.0

12.8

16.3

39.3

31.6

3.4

77.8

18.8

53.8

31.6

14.5

35.1

41.0

23.9

Stage at diagnosis

Stage 0

Stage I

Stage II

Stage III

Stage IV

Type of surgery

Breast conserving surgery

Mastectomy

Radiotherapy

Yes

No

Chemotherapy
Table 1 Socio-demographic and disease characteristics of participants $(n=117)$ (Continued)

\begin{tabular}{lcc}
\hline Yes & 84 & 71.8 \\
No & 33 & 28.2 \\
Hormone therapy $^{a}$ & & \\
Yes & 92 & 79.3 \\
No & 24 & 20.7 \\
Immune therapy ${ }^{\mathrm{a}}$ & & 22.6 \\
Yes & 26 & 77.4 \\
No & 89 &
\end{tabular}

About $43.0 \%$ of the participants had been diagnosed with breast cancer less than 2 years ago. More than onethird of the participants $(36.8 \%)$ were diagnosed at stage II, followed by $23.9 \%$ at stage III. While $20.5 \%$ was diagnosed with stage I and others in stage IV. Regarding the treatment modalities, the majority of the participants (68.4 \%) underwent mastectomy, $80.3 \%$ received radiotherapy, $71.8 \%$ had chemotherapy and $79.3 \%$ had hormone therapy.

\section{Most common unmet supportive care needs}

The most commonly reported unmet supportive care needs were found all in the psychological domain, followed by physical domain. Table 2 represents the percentages of some unmet supportive care needs of individual items of SCNS-SF 34 among the participants. Most prevalent unmet supportive care needs in the psychological domain were uncertainty about the future (78.6\%), followed by fears about the cancer spreading (76.1 \%), feelings of sadness (69.2 \%), feelings about death and dying (68.4\%), concerns about the worries of those close to the patient $(65.0 \%)$, worries that the results of treatment are beyond control $(65.0 \%)$ and feeling down or depressed (65.0\%). Most prevalent unmet supportive care needs in the physical domain were feeling unwell a lot of the time (58.1\%), followed by lack of energy/tiredness $(57.3 \%)$ and pain (55.6\%). In the sexuality domain the most prevalent unmet supportive care need was changes in sexual relationships (35.0 \%). In the patient care domain and health system information domain, the percentage of some unmet supportive care needs was very low except the choices about specialists the patients see (45.3\%).

Table 3 summarizes the mean and median score of the supportive care needs scale of SCNS-SF 34 among the participants. Among all the supportive care needs domain of SCNS-SF 34, psychological needs were observed to have the highest mean $(53.31 \pm 21.79)$, followed by physical needs $(38.16 \pm 27.15)$. The lowest 
Table 2 Some unmet supportive care needs of individual item of SCNS-SF 34 among the study sample

\begin{tabular}{|c|c|}
\hline Some unmet supportive care needs & N (\%) \\
\hline \multicolumn{2}{|l|}{ Physical } \\
\hline Pain & $65(55.6)$ \\
\hline Lack of energy/tiredness & $67(57.3)$ \\
\hline Feeling unwell a lot of the time & $68(58.1)$ \\
\hline Work around the home & $45(38.5)$ \\
\hline Not being able to do the things you used to do & $43(36.8)$ \\
\hline \multicolumn{2}{|l|}{ Psychological } \\
\hline Anxiety & $65(55.6)$ \\
\hline Feeling down or depressed & $76(65.0)$ \\
\hline Feelings of sadness & $81(69.2)$ \\
\hline Fears about the cancer spreading & $89(76.1)$ \\
\hline Worry that the results of treatment are beyond your control & $76(65.0)$ \\
\hline Uncertainty about the future & $92(78.6)$ \\
\hline Learning to feel in control of your situation & $55(47.0)$ \\
\hline Keeping a positive outlook & $60(51.3)$ \\
\hline Feelings about death and dying & $80(68.4)$ \\
\hline Concerns about the worries of those close to you & $76(65.0)$ \\
\hline \multicolumn{2}{|l|}{ Sexuality } \\
\hline Changes in sexual feelings & $40(34.2)$ \\
\hline Changes in your sexual relationships & $41(35.0)$ \\
\hline Being given information about sexual relationships & $25(21.4)$ \\
\hline \multicolumn{2}{|l|}{ Patient Care } \\
\hline More choice about which cancer specialists you see & $53(45.3)$ \\
\hline More choice about which hospital you attend & $42(35.9)$ \\
\hline Reassurance by medical staff that the way you feel is normal & $38(32.5)$ \\
\hline Hospital staff attending promptly to your physical needs & $35(29.9)$ \\
\hline Hospital staff acknowledging, and showing sensitivity to, your feelings and emotional needs & $45(38.5)$ \\
\hline \multicolumn{2}{|l|}{ Health System Information } \\
\hline Being given written information about the important aspects of your care & $14(12.0)$ \\
\hline Being given information (written, diagrams, drawings) about aspects of managing your illness and side-effects at home & $32(27.4)$ \\
\hline Being given explanations of those tests for which you would like explanations & $35(29.9)$ \\
\hline Being adequately informed about the benefits and side-effects of treatments before you choose to have them & $27(23.1)$ \\
\hline Being informed about your test results as soon as feasible & $14(12.0)$ \\
\hline Being informed about cancer which is under control or diminishing (that is, remission) & $24(20.5)$ \\
\hline Being informed about things you can do to help yourself to get well & $21(17.9)$ \\
\hline Having access to professional counselling (e.g. psychologist, social worker, counsellor, nurse specialist) if you, family or friends need it & $17(14.5)$ \\
\hline Being treated like a person not just another case & $25(21.4)$ \\
\hline Being treated in a hospital or clinic that is as physically pleasant as possible & $20(17.1)$ \\
\hline Having one member of hospital staff with whom you can talk to about all aspects of your condition, treatment and follow-up & $16(13.7)$ \\
\hline
\end{tabular}

mean score domain was observed in sexuality $(27.78$ $\pm 21.91)$. The mean score for the patient care needs was $37.65( \pm 16.45)$ and for health information needs was $31.53( \pm 12.17)$.
Association between global QOL, participants' characteristics and supportive care needs

Participants' socio-demographic and disease characteristics as well as their supportive care needs were examined 
Table 3 Mean and median score of supportive care needs scale of SCNS-SF 34 among the study population

\begin{tabular}{lll}
\hline Variables & Mean $(\underline{+}$ SD) & Median (Range) \\
\hline Physical needs & $38.16(27.15)$ & $40(0-100)$ \\
Psychological needs & $53.31(21.79)$ & $52.50(10-92.50)$ \\
Sexuality needs & $27.78(21.91)$ & $25(0-91.67)$ \\
Patient care needs & $37.65(16.45)$ & $30(25-85)$ \\
Health information needs & $31.53(12.17)$ & $25(20.45-77.27)$ \\
\hline
\end{tabular}

for their association with global QOL (Table 4). Multiple linear regression analyses, using those variables with $p$ values $<0.25$ in univariate analyses as candidate variables, revealed that time since diagnosis $(\beta=0.177 ; p$ value $=0.003)$, stage at diagnosis of breast cancer $(\beta=$ $-0.215 ; p$ value $=0.008)$, physical $(\beta=-0.346 ; p$ value $=$ $0.001)$ and psychological unmet needs $(\beta=-0.218 ; p$ value $=0.004$ ) were independently associated with $\mathrm{QOL}$ among the breast cancer patients. Early breast cancer survivors with advanced stage diagnosis who had greater physical and psychological needs were significantly $(p<$ $0.05)$ associated with poor QOL. The adjuste $R^{2}$ for this model was 0.780 that means $78.0 \%$ variability of the outcome is explained by this model. The regression model was highly significant, $p<0.001$.

In summary, the most common unmet supportive care needs were found to be in the psychological domain. Early breast cancer survivors, diagnosed at an advanced stage who had greater physical and psychological needs were likely to have a poorer quality of life.

\section{Discussion}

This is the first study addressing the supportive care needs of breast cancer patients in Malaysia. It reveals a multitude of unmet supportive care needs of breast cancer patients in all the domains with highest prevalence in the psychological domain, followed by physical, patient care needs, health information and lowest in sexuality domain. The most prevalent unmet psychological needs of the breast cancer patients reported in this study were uncertainty about the future, fears about the cancer spreading, feelings of sadness, feelings about death and dying, concerns about those close to the patient, worry that the results of treatment are beyond control and feeling down or depressed. In western countries unmet needs were highest in psychological domain which is consistent with the findings of this study [36, 42, 43]. Whereas in Asian developing countries unmet needs were mostly related to health system information [17, 44-47]. As a matter of fact, supportive care needs are the product of perspective of culture and interaction of psychology based on cultural context [30]. With the westernization, the perception of cancer and unmet needs of the cancer patients has been changing over few decades in Malaysia [48]. It should also be noted that most of the breast cancer patients in this study had completed their initial course of treatment less than 5 years ago and it is possible that the psychological supportive care needs had not dissipated by the time they participated in the study. It has found that psychological distress of breast cancer patients were higher among those with survival duration of less than 5 years than those with long-term survival more than 5 years [29]. Nevertheless, in Malaysian healthcare settings, providing services of psychosocial components of care for cancer patients are not yet well established [48]. Incorporation of psychosocial components of care in the routine cancer care delivery in healthcare settings is crucial and can be challenging as there is no existing training, guidelines and strategies for the healthcare providers in Malaysia. Studies suggest that addressing psychological needs can have a great role in helping women with breast cancer in the long-term adjustment process and improving their QOL $[28,49,50]$.

Particularly amongst various types of physical needs, breast cancer patients had stronger needs in their physical strength and dealing with pain. These could be the residual side effects or late onset symptoms of breast cancer treatment which should be monitored timely to characterize the level of unmet needs over time. There is a growing volume of literatures which support the proposition that lack of physical strength and pain are the critical physical needs among the breast cancer patients throughout the period of treatment and survivorship [8,51]. The experience of these persistent symptoms and morbidities as well as associated unmet needs could significantly hamper their QOL and successful transition from early to long-term survivorship [4]. These findings have important clinical implication in providing timely and appropriate physical rehabilitation depending on the needs in healthcare setting after the initial course of breast cancer treatment.

In Malaysian healthcare system, breast cancer patients have a regular access to healthcare professionals during their therapy and in the post treatment period, which develops confidence over the clinical team concerning the treatment [52]. Therefore, the patient care and health system and information needs might seem to be very low except many had a need to have more choices concerning the cancer specialists they see. A possible explanation could be a divergence between their expectations to have more opinions for the assurance that quickly they would cope up and come back to normal life.

Congruent with other studies, it was expected to find sexuality domain as least unmet needs in this study $[44,53]$. However, the findings may not reflect the actual 
Table 4 Association between global quality of life, participants' characteristics and supportive care needs

\begin{tabular}{|c|c|c|c|c|c|c|}
\hline \multirow[t]{2}{*}{ Variables } & \multicolumn{2}{|c|}{ Univariate analysis } & \multicolumn{4}{|c|}{ Multivariate analysis $^{a}$} \\
\hline & Mean (SD) & $p$ value & $B$ & SE & $\beta$ & $p$ value \\
\hline \multicolumn{7}{|c|}{ Socio-demographic and disease characteristics } \\
\hline Age & & & -0.282 & 1.647 & -0.011 & 0.864 \\
\hline$<40$ years & $79.69(12.53)$ & & & & & \\
\hline $40-49$ years & $71.26(18.44)$ & 0.004 & & & & \\
\hline$\geq 50$ years & $63.77(19.08)$ & & & & & \\
\hline Ethnicity & & & -0.038 & 1.452 & -0.002 & 0.979 \\
\hline Malay & $61.15(18.64)$ & & & & & \\
\hline Chinese & $76.19(14.23)$ & 0.001 & & & & \\
\hline Indian & $77.38(17.86)$ & & & & & \\
\hline Educational Level & & & 2.785 & 1.912 & 0.146 & 0.148 \\
\hline No formal education & $44.44(12.06)$ & & & & & \\
\hline Primary & $58.33(20.41)$ & 0.001 & & & & \\
\hline Secondary & $68.12(15.34)$ & & & & & \\
\hline Tertiary & $81.76(10.90)$ & & & & & \\
\hline Marital Status & & & 0.941 & 2.592 & 0.022 & 0.717 \\
\hline Unmarried & $72.92(15.77)$ & & & & & \\
\hline Married & $69.96(18.54)$ & 0.023 & & & & \\
\hline Divorced/widowed & $57.95(18.62)$ & & & & & \\
\hline Employment Status & & & -2.736 & 2.256 & -0.104 & 0.228 \\
\hline Housewife & $58.46(17.74)$ & & & & & \\
\hline Employed & $81.30(11.01)$ & 0.001 & & & & \\
\hline Retired & $73.04(17.56)$ & & & & & \\
\hline Household Income (RM) & & & 3.231 & 2.176 & 0.130 & 0.141 \\
\hline Less than 2000 & $50.61(13.61)$ & & & & & \\
\hline RM2000- 4000 & $74.48(15.41)$ & 0.001 & & & & \\
\hline More than 4000 & $81.55(11.19)$ & & & & & \\
\hline Time since Diagnosis & & & 4.746 & 1.573 & 0.177 & 0.003 \\
\hline$<2$ years & $62.83(19.21)$ & & & & & \\
\hline $2-5$ years & $67.00(18.43)$ & 0.001 & & & & \\
\hline$>5$ years & $84.80(6.06)$ & & & & & \\
\hline Stage at Diagnosis & & & -3.776 & 1.385 & -0.215 & 0.008 \\
\hline Stage 0 & $79.16(7.71)$ & & & & & \\
\hline Stage 1 & $77.08(12.83)$ & & & & & \\
\hline Stage 2 & $70.73(17.19)$ & 0.001 & & & & \\
\hline Stage 3 & $65.18(19.51)$ & & & & & \\
\hline Stage 4 & $41.67(10.34)$ & & & & & \\
\hline Type of Surgery & & & -1.668 & 2.947 & -0.041 & 0.573 \\
\hline Breast conserving surgery & $74.32(12.79)$ & 0.011 & & & & \\
\hline Mastectomy & $64.79(20.54)$ & & & & & \\
\hline Radiotherapy & & & 3.499 & 4.999 & 0.074 & 0.486 \\
\hline Yes & $64.45(19.40)$ & 0.001 & & & & \\
\hline No & $81.52(7.08)$ & & & & & \\
\hline
\end{tabular}


Table 4 Association between global quality of life, participants' characteristics and supportive care needs (Continued)

\begin{tabular}{|c|c|c|c|c|c|c|}
\hline Chemotherapy & & & -5.305 & 4.173 & -0.127 & 0.207 \\
\hline Yes & $62.79(19.59)$ & 0.001 & & & & \\
\hline No & $80.55(8.24)$ & & & & & \\
\hline Hormone therapy & & & 3.502 & 4.020 & 0.075 & 0.386 \\
\hline Yes & $64.67(19.43)$ & 0.001 & & & & \\
\hline No & $80.56(9.41)$ & & & & & \\
\hline Immune therapy & & & -3.396 & 2.963 & -0.075 & 0.255 \\
\hline Yes & $75.96(17.69)$ & 0.013 & & & & \\
\hline No & $65.54(18.81)$ & & & & & \\
\hline Unmet Supportive Care Needs & Correlation coefficient & & & & & \\
\hline Physical Needs & -0.76 & 0.001 & -0.241 & 0.070 & -0.346 & 0.001 \\
\hline Psychological Needs & -0.80 & 0.001 & -0.191 & 0.094 & -0.218 & 0.004 \\
\hline Sexuality Needs & -0.06 & 0.553 & NS & NS & NS & NS \\
\hline Patient's Care Needs & -0.44 & 0.001 & -0.028 & 0.103 & -0.024 & 0.787 \\
\hline Health Information Needs & -0.16 & 0.092 & 0.009 & 0.122 & 0.006 & 0.941 \\
\hline
\end{tabular}

${ }^{a}$ Multiple linear regression model included 117 participants with complete covariate information

B: Regression coefficient, SE: Standard error of regression coefficient, $\beta$ : Standardized regression coefficient, NS: Not significant and not being entered into multiple linear regression ( $p$ value $>0.25$ ), $p$ value $<0.05$ is considered as statistically significant

status in a conservative society like Malaysia where conservative cultural values consider talking about sexuality is embarrassing [54]. Moreover, this would eventually make patients to perceive that sexuality is a low priority despite having certain sexual problems. Although impairment in sexual functioning has significant negative impact on psychological well-being and QOL $[55,56]$.

In multivariate analysis, the results showed that early breast cancer survivors diagnosed at an advanced stage with higher levels of physical and psychological unmet needs were more likely to have an overall poor QOL. Breast cancer patients with late stage diagnosis invariably require a lengthy and complicated course of treatment $[4,6,8]$. As seen in other studies, the unanticipated side effects and the struggle through the lengthy and disruptive treatment procedure might give rise to the psychological and physical difficulties to the breast cancer patients $[4,36,44,46,57-59]$. It is not unlikely that poor psychological adjustment might enhance physical disability or vice versa [33]. The complicated long-term treatment which led to physical and psychological sufferings makes early breast cancer survivors' lives miserable. Breast cancer patients certainly need time to get over the burdens of side effects of the longterm treatment $[3,12]$. Therefore, continuous and timely psychological support and physical rehabilitation may have contributed to reduce their chronic sufferings, helped them with the adjustment process over and after the course of long-term treatment and could possibly enhance their QOL.

This study had several limitations. The research was conducted to the surgery and oncology outpatients of a single large government academic hospital, which limits the applicability of the findings to the breast cancer patients all over Malaysia. The patients were recruited by universal sampling, which led to sampling bias. Several types of response bias may also be possible while collecting data. Acquiescence bias is one of those where participants tend to answer questions affirmatively when they have doubts. Another is a central tendency bias where participants tend to avoid extreme scores and give response towards the centre of the scale range. Questions on sexuality may not have been answered truthfully due to cultural barriers which may cause information bias.

\section{Conclusion}

The unmet needs among the breast cancer patients were found predominant in the psychological and physical domain. Hence, most prevalent unmet needs were found in the psychological domain. Early breast cancer survivors with late stage diagnosis, who had greater unmet needs in the physical and psychological domains were more likely to have a poor QOL. The research findings provide comprehensive insight into unmet needs of breast cancer patients across a range of domains for well-directed and effective management in clinical-follow up. However, it emphasizes that rendering timely and appropriate psychological and physical rehabilitation programmes in healthcare setting ought to be the highest priority to support them in the long-term adjustment process and ensure a better QOL.

\section{Competing interests}

This study is funded by International Medical University [Research Project: M.SCPHI01/2014(01)]. 
The authors declare that they have no financial and non-financial competing interests.

\section{Authors' contributions}

Author ZE designed the study, wrote the protocol, prepare the questionnaire, supervised data collection, performed the statistical analysis, interpreted the results, and wrote the drafts of the manuscript. Author VK helped in designing the study, reviewing the results and discussion. NBA, AMR and SARAD helped to get permission from University Kebangsaan Malaysia Medical Centre, prepare the questionnaire and to draft the manuscript. All authors read and approved the final manuscript.

\section{Acknowledgement}

The authors would like to thank Dr Hematram Yadav from International Medical University for giving ideas for the research proposal. The authors would also like to thank the women who gave so generously of their time to participate in this study.

\section{Author details}

'Department of Community Medicine, International Medical University, Bukit Jalil 57000 Kuala Lumpur, Malaysia. ${ }^{2}$ Department of Surgery, Universiti Kebangsaan Malaysia Medical Centre, Cheras 56000Kuala Lumpur, Malaysia. 3.Department of Community Health, Faculty of Medicine, Universiti Kebangsaan Malaysia Medical Centre, Cheras 56000Kuala Lumpur, Malaysia. ${ }^{4}$ Faculty of Medicine, SEGi University, Kota Damansara, 47810 Petaling Jaya, Selangor, Malaysia.

Received: 3 July 2015 Accepted: 12 February 2016 Published online: 22 February 2016

\section{References}

1. Latest world cancer statistics Global cancer burden rises to 14.1 million new cases in 2012: Marked increase in breast cancers must be addressed December 2013. Date accessed: 27th April, 2014: [1-3pp.]. Available from: http://www.iarcfr/en/mediacentre/pr/2013/pdfs/pr223_E.pdf.

2. Jemal A, Bray F, Center MM, Ferlay J, Ward E, Forman D. Global cancer statistics. CA Cancer J Clin. 2011;61(2):69-90.

3. De Aguiar SS, Bergmann A, Mattos IE. Quality of life as a predictor of overall survival after breast cancer treatment. Quality of Life Research. 2014;23(2): 627-637.

4. Cheng K, Darshini Devi R, Wong W, Koh C. Perceived symptoms and the supportive care needs of breast cancer survivors six months to five years post-treatment period. European Journal of Oncology Nursing. 2014;18(1):3-9.

5. DeSantis C, Ma J, Bryan L, Jemal A. Breast cancer statistics, 2013. CA Cance J Clin. 2014;64(1):52-62.

6. DeSantis C, Siegel R, Jemal A. American Cancer Society. Breast cancer facts and figures 2013-2014. Atlanta: American Cancer Society, Inc. 2013.

7. Abdullah NA, Wan Mahiyuddin W, Muhammad NA, Ali ZM, Ibrahim L, Ibrahim Tamim N. Survival rate of breast cancer patients in Malaysia: a population-based study. Asian Pac J Cancer Prev. 2013;14(8):4591-4.

8. Shi Q, Smith TG, Michonski JD, Stein KD, Kaw C, Cleeland CS. Symptom burden in cancer survivors 1 year after diagnosis. Cancer. 2011;117(12):2779-90.

9. Liao M-N, Chen S-C, Lin Y-C, Chen M-F, Wang C-H, Jane S-W. Education and psychological support meet the supportive care needs of Taiwanese women three months after surgery for newly diagnosed breast cancer: A non-randomised quasi-experimental study. Int J Nurs Stud. 2014;51(3):390-9.

10. Montazeri A, Vahdaninia M, Harirchi I, Ebrahimi M, Khaleghi F, Jarvandi S. Quality of life in patients with breast cancer before and after diagnosis: an eighteen months follow-up study. BMC Cancer. 2008:8(1):330.

11. Matalqah LM, Radaideh KM, Yusoff ZM, Awaisu A. Health-related quality of life using EQ-5D among breast cancer survivors in comparison with agematched peers from the general population in the state of Penang, Malaysia. J Public Health. 2011;19(5):475-80.

12. Rosedale M, Fu MR. Confronting the unexpected: temporal, situational, and attributive dimensions of distressing symptom experience for breast cancer survivors. Oncology nursing forum. 2010; 37(1):28-33.

13. Gysels M, Higginson IJ, Rajasekaran M, Davies E, Harding R. Improving supportive and palliative care for adults with cancer. Research Evidence Manual London. England: National Institute of Clinical Excellence; 2004.

14. Au H-y, Angel. What are the unmet supportive care needs among Hong Kong Chinese womenwith advanced breast cancer?: do they changeover time? The University of Hong Kong scholars hub(Pokfulam, Hong Kong): The University of Hong Kong (Pokfulam, Hong Kong); 2012.

15. Harrison JD, Young JM, Price MA, Butow PN, Solomon MJ. What are the unmet supportive care needs of people with cancer? A systematic review. Support Care Cancer. 2009;17(8):1117-28.

16. Li WW, Lam WW, Au AH, Ye M, Law WL, Poon J, et al. Interpreting differences in patterns of supportive care needs between patients with breast cancer and patients with colorectal cancer. Psycho-Oncology. 2013;22(4):792-8

17. Chan DN-S, Choi K-C, Chan CW-H, Wan RW-M, Mak SS-S, Wong EM-L, et al. Supportive care needs and health-related quality of life among Chinese lung cancer survivors. Adv Lung Cancer. 2012;1(02):5.

18. Minstrell M, Winzenberg T, Rankin N, Hughes C, Walker J. Supportive care of rural women with breast cancer in Tasmania, Australia: changing needs over time. Psycho-Oncology. 2008:17(1):58-65.

19. Tager FA, McKinley PS, Schnabel FR, El-Tamer M, Cheung YKK, Fang Y, et al. The cognitive effects of chemotherapy in post-menopausal breast cancer patients: a controlled longitudinal study. Breast Cancer Res Treat. 2010; 123(1):25-34.

20. Amatya B, Khan F, Ng L, Galea M. Supportive Care Needs following Cancer Treatment: A Comparison of Breast and Brain Cancer in an Australian Cohort. ISRN Rehabilitation. 2014; Article ID 945472. Available from: http://dx.doi.org/10.1155/2014/945472.

21. Björneklett $H G$, Rosenblad A, Lindemalm C, Ojutkangas $M-L$, Letocha $H$, Strang $\mathrm{P}$, et al. Long-term follow-up of a randomized study of support group intervention in women with primary breast cancer. J Psychosom Res. 2013;74(4):346-53.

22. Usta YY. Importance of Social Support in Cancer Patients. Asian Pac J Cancer Prev. 2012;13(8):3569-72.

23. Trunzo JJ, Pinto BM. Social support as a mediator of optimism and distress in breast cancer survivors. J Consult Clin Psychol. 2003;71(4):805.

24. Kroenke CH, Kwan ML, Neugut Al, Ergas IJ, Wright JD, Caan BJ, et al. Social networks, social support mechanisms, and quality of life after breast cancer diagnosis. Breast Cancer Res Treat. 2013:139(2):515-27.

25. Adler NE, Page AE, editors. Cancer Care for the Whole Patient: Meeting Psychosocial Health Needs. National Academies Press; 2008.

26. Osse BH, Vernooij-Dassen MJ, Schadé E, Grol RP. The problems experienced by patients with cancer and their needs for palliative care. Support Care Cancer. 2005;13(9):722-32.

27. Epplein M, Zheng Y, Zheng W, Chen Z, Gu K, Penson D, et al. Quality of life after breast cancer diagnosis and survival. J Clin Oncol. 2011;29(4):406-12.

28. Uchida M, Akechi T, Okuyama T, Sagawa R, Nakaguchi T, Endo C et al. Patients' supportive care needs and psychological distress in advanced breast cancer patients in Japan. Japanese journal of clinical oncology. 2011; 41(4):530-536

29. Park BW, Hwang SY. Unmet needs of breast cancer patients relative to survival duration. Yonsei Med J. 2012:53(1):118-25.

30. Lam WW, Au AH, Wong JH, Lehmann C, Koch U, Fielding R, et al. Unmet supportive care needs: a cross-cultural comparison between Hong Kong Chinese and German Caucasian women with breast cancer. Breast Cancer Res Treat. 2011;130(2):531-41.

31. Carlson LE, Waller A, Mitchell AJ. Screening for distress and unmet needs in patients with cancer: review and recommendations. Journal of Clinical Oncology. 2012:JCO. 2011.39. 5509.

32. Butow PN, Phillips F, Schweder J, White K, Underhill C, Goldstein D. Psychosocial well-being and supportive care needs of cancer patients living in urban and rural/regional areas: a systematic review. Support Care Cancer. 2012;20(1):1-22.

33. Akechi T, Okuyama T, Endo C, Sagawa R, Uchida M, Nakaguchi T, et al. Patient's perceived need and psychological distress and/or quality of life in ambulatory breast cancer patients in Japan. Psycho-Oncology. 2011;20(5):497-505.

34. Husson O, Mols F, Van de Poll-Franse L. The relation between information provision and health-related quality of life, anxiety and depression among cancer survivors: a systematic review. Ann Oncol. 2011:22(4):761-72.

35. Shim E-J, Mehnert A, Koyama A, Cho S-J, Inui H, Paik N-S, et al. Health-related quality of life in breast cancer: A cross-cultural survey of German, Japanese, and South Korean patients. Breast Cancer Res Treat. 2006;99(3):341-50.

36. Mehnert A, Koch U. Psychological comorbidity and health-related quality of life and its association with awareness, utilization, and need for psychosocial support in a cancer register-based sample of long-term breast cancer survivors. J Psychosom Res. 2008;64(4):383-91. 
37. Carlson LE, Bultz BD. Efficacy and medical cost offset of psychosocial interventions in cancer care: making the case for economic analyses. Psycho-Oncology. 2004;13(12):837-49.

38. Boyes A, Girgis A, Lecathelinais C. Brief assessment of adult cancer patients' perceived needs: development and validation of the 34-item Supportive Care Needs Survey (SCNS-SF34). J Eval Clin Pract. 2009;15(4):602-6.

39. McElduff P, Boyes A, Zucca A, Girgis A. Supportive Care Needs Survey: A guide to administration, scoring and analysis. Newcastle: Centre for Health Research \& Psycho-oncology; 2004.

40. Fayers PM, Aaronson N, Bjordal K, Groenveld M, Curran D, Bottomley A. The EORTC QLQ-C30 Scoring Manual Published by: European Organisation for Research and Treatment of Cancer. Brussels, Belgium. 2001.

41. Hjermstad MJ, Fossa SD, Bjordal K, Kaasa S. Test/retest study of the European Organization for Research and Treatment of Cancer Core Qualityof-Life Questionnaire. J Clin Oncol. 1995:13(5):1249-54.

42. Brédart A, Kop J-L, Griesser A-C, Fiszer C, Zaman K, Panes-Ruedin B et al. Assessment of needs, health-related quality of life, and satisfaction with care in breast cancer patients to better target supportive care. Annals of oncology. 2013; 24(8):2151-2158.

43. Knobf MT, Ferrucci LM, Cartmel B, Jones BA, Stevens D, Smith M, et al. Needs assessment of cancer survivors in Connecticut. J Cancer Survivorship. 2012;6(1):1-10.

44. So WK, Chow KM, Chan HY, Choi KC, Wan RW, Mak SS, et al. Quality of life and most prevalent unmet needs of Chinese breast cancer survivors at one year after cancer treatment. Eur J Oncol Nurs. 2014;18(3):323-8.

45. Singh-Carlson S, Wong F, Martin L, Nguyen SK. Breast cancer survivorship and South Asian women: understanding about the follow-up care plan and perspectives and preferences for information post treatment. Current Oncology. 2013;20(2):e63-79.

46. So WK, Chan CW, Choi K, Wan RW, Mak SS. Perceived unmet needs and health-related quality of life of Chinese cancer survivors at 1 year after treatment. Cancer Nurs. 2013;36(3):E23-32.

47. Hwang SY, Park B-W. The perceived care needs of breast cancer patients in Korea. Yonsei Med J. 2006:47(4):524-33.

48. Pathy NB, Yip CH, Taib NA, Hartman M, Saxena N, lau P, et al. Breast cancer in a multi-ethnic Asian setting: Results from the Singapore-Malaysia hospital-based breast cancer registry. Breast. 2011;20:S75-80.

49. Liao M-N, Chen S-C, Chen S-C, Lin Y-C, Hsu Y-H, Hung H-C et al., editors. Changes and predictors of unmet supportive care needs in Taiwanese women with newly diagnosed breast cancer. Oncology nursing forum. 2012; 39(5):E380-E389.

50. Distelhorst SR, Cleary JF, Ganz PA, Bese N, Camacho-Rodriguez R, Cardoso F, et al. Optimisation of the continuum of supportive and palliative care for patients with breast cancer in low-income and middle-income countries: executive summary of the Breast Health Global Initiative, 2014. Lancet Oncol. 2015;16(3):e137-47.

51. Berger AM, Visovsky C, Hertzog M, Holtz S, Loberiza Jr FR. Usual and worst symptom severity and interference with function in breast cancer survivors. J Support Oncol. 2012;10(3):112-8.

52. Dahlui M, Ramli S, Bulgiba AM. Breast cancer prevention and control programs in Malaysia. Asian Pac J Cancer Prev. 2011;12(6):1631-4.

53. Au A, Lam W, Tsang J, Yau T, Soong I, Yeo W, et al. Supportive care needs in Hong Kong Chinese women confronting advanced breast cancer. Psycho-Oncology. 2013;22(5):1144-51.

54. Gu C, Chan CW, Twinn S. How sexual history and knowledge of cervical cancer and screening influence Chinese women's screening behavior in mainland China. Cancer Nurs. 2010;33(6):445-53.

55. Chow KM, Chan C, Choi K, Shiu A, Cheng K, Ip W, et al. Psychometric properties of the Chinese version of Sexual Function after Gynecologic IIIness Scale (SFAGIS). Support Care Cancer. 2013;21(11):3079-84.

56. Ussher JM, Perz J, Gilbert E. Changes to sexual well-being and intimacy after breast cancer. Cancer Nurs. 2012;35(6):456-65.

57. Fiszer C, Dolbeault S, Sultan S, Brédart A. Prevalence, intensity, and predictors of the supportive care needs of women diagnosed with breast cancer: a systematic review. Psycho-Oncology. 2014;23(4):361-74.
58. Pearce MJ, Coan AD, Herndon II JE, Koenig HG, Abernethy AP. Unmet spiritual care needs impact emotional and spiritual well-being in advanced cancer patients. Support Care Cancer. 2012;20(10):2269-76.

59. Carey M, Lambert S, Smits R, Paul C, Sanson-Fisher R, Clinton-McHarg T. The unfulfilled promise: a systematic review of interventions to reduce the unmet supportive care needs of cancer patients. Support Care Cancer. 2012;20(2):207-19.

\section{Submit your next manuscript to BioMed Central and we will help you at every step:}

- We accept pre-submission inquiries

- Our selector tool helps you to find the most relevant journal

- We provide round the clock customer support

- Convenient online submission

- Thorough peer review

- Inclusion in PubMed and all major indexing services

- Maximum visibility for your research

Submit your manuscript at www.biomedcentral.com/submit
Biomed Central 